NASA

Technical Memorandum 106647

AIAA-94-3366
Army Research Laboratory

Technical Report ARL-TR-493

\title{
Comparison of Transmission Error Predictions With Noise Measurements for Several Spur and Helical Gears
}

Donald R. Houser

The Ohio State University

Columbus, Ohio

Fred B. Oswald

Lewis Research Center

Cleveland, Ohio

Mark J. Valco

Vehicle Propulsion Directorate

U.S. Army Research Laboratory

Lewis Research Center

Cleveland, Ohio

Raymond J. Drago and Joseph W. Lenski, Jr.

Boeing Helicopters

Philadelphia, Pennsylvania

Prepared for the

30th Joint Propulsion Conference

cosponsored by the AIAA, ASME, SAE, and ASEE

Indianapolis, Indiana, June 27-29, 1994
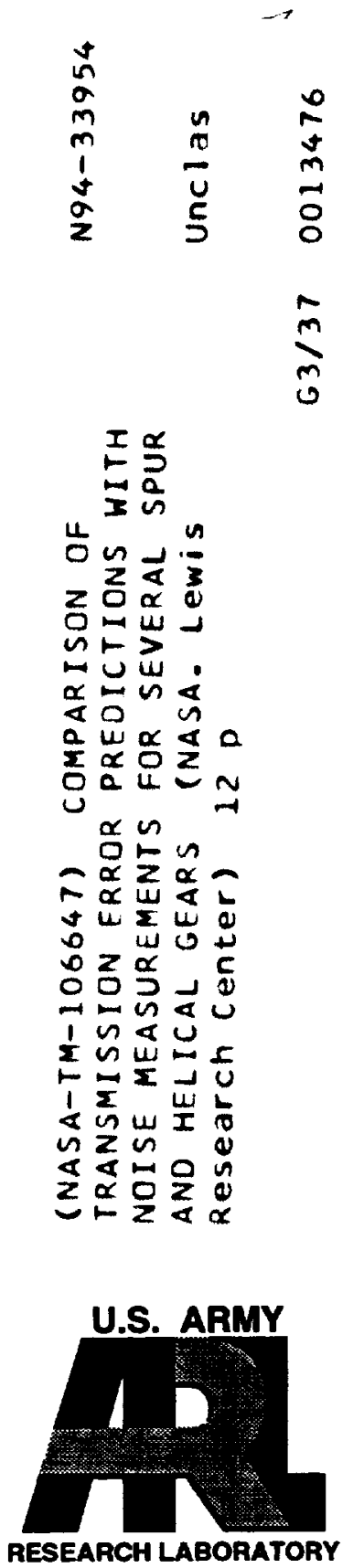


\section{COMPARISON OF TRANSMISSION ERROR PREDICTIONS WITH NOISE MEASUREMENTS FOR SEVERAL SPUR AND HELICAL GEARS}

\author{
Donald R. Houser \\ The Ohio State University \\ Columbus, Ohio \\ Mark J. Valco \\ U.S. Army Research Laboratory \\ Lewis Research Center \\ Cleveland, Ohio
}

\author{
Fred B. Oswald \\ National Aeronautics and Space Administration \\ Lewis Research Center \\ Cleveland, Ohio \\ Raymond J. Drago and Joseph W. Lenski, Jr. \\ Boeing Helicopters \\ Philadelphia, Pennsylvania
}

\begin{abstract}
$\underline{\text { Abstract }}$
Measured sound power data from eight different spur, single and double helical gear designs are compared with predictions of transmission error by the Load Distribution Program. The sound power data was taken from the recent Army-funded Advanced Rotorcraft Transmission project. Tests were conducted in the NASA gear noise rig. Results of both test data and transmission error predictions are made for each harmonic of mesh frequency at several operating conditions. In general, the transmission error predictions compare favorably with the measured noise levels.
\end{abstract}

\section{Introduction}

There has long been a strong feeling that transmission error is closely related to the noise emitted by gear pairs [17]. However, few direct comparisons of transmission error predictions with actual measured sound data exist. Although transmission error predictions have been made by several investigators [5-7], there have been few published efforts that attempt to corroborate predictions with systematically designed experimental tests. The most convincing of the comparisons that has been performed is that of Kubo [11], who, after performing some adjustments to account for manufacturing variations from tooth to tooth, shows a good correlation between noise and predicted transmission error for several similar geometry gear sets. The literature [8-11] shows that many people have investigated the effects of different gear geometries on noise, but few have made controlled measurement of different geometries in one housing.

In a study to create a data base for gear noise assessment, Drago et al. [12] designed and made gears of eight different geometries. The gears were tested in a NASA-Lewis gear noise test rig. A logical follow-up of the acquisition of test data is the comparison of the data to transmission error models. This paper uses a computer model called the Load Distribution Program (LDP), a program that predicts transmission error for all types of parallel axis gears [7], to model the gears and to compare the predictions to the measured results. The results presented show a good correlation between the predictions and measured data.

\section{Test Data}

The test gears were driven by an electric motor and loaded with an electric dynamometer. The test gears were mounted on shafts in a 3.5 inch center distance housing. Some power measurements reported in [12] were taken with an acoustic intensity probe scanned over a prescribed measurement grid just above the top of the gear box. Reported sound power measurements were the sum of the amplitudes of the frequency peaks at the first three mesh harmonics and the amplitudes of the significant sidebands around each mesh harmonic. Further details of the test rig and measurement procedures are reported in [12].

The basic gear geometry is given in Table 1 and the 8 gear pairs tested are summarized in Table 2 . The profile contact ratios and face contact ratios, which differ slightly from those given by Drago, et al. [12], were computed by using tooth tip roll angles taken from profile inspection charts. Henceforth, gear pairs will be referred to with the numbers given in the first column of Table 2 and the letters following each number will indicate the torque loading (an A indicates the lowest torque of $1361 \mathrm{lbf}-\mathrm{in}$. and a $\mathrm{C}$ indicates the highest torque of $2269 \mathrm{lbf}-\mathrm{in}$.).

\section{Test Gears and Test Parameters}

The test gear pairs chosen in Table 2 . provide a broad range of geometries including a baseline spur gear pair, a

Table 1. Test Gear Configuration

\begin{tabular}{|l|c|c|}
\cline { 2 - 3 } \multicolumn{1}{c|}{} & Pinion & Gear \\
\hline Number of Teeth & 25 & 31 \\
\hline $\begin{array}{l}\text { Diametral Pitch, } \\
\text { Transverse }\end{array}$ & \multicolumn{2}{|c|}{8.00} \\
\hline Center Distance & \multicolumn{2}{|c|}{3.50} \\
\hline $\begin{array}{l}\text { Pressure Angle, } \\
\text { Transverse }\end{array}$ & $\begin{array}{l}25 \text { (Std Profile Contact Ratio) } \\
20 \text { (High Profile Contact Ratio) }\end{array}$ \\
\hline $\begin{array}{l}\text { Face Width } \\
\text { (Spur \& Single Helical) }\end{array}$ & \multicolumn{2}{|c|}{1.25} \\
\hline $\begin{array}{l}\text { Face Width } \\
\text { (Double Helical) }\end{array}$ & Double Helicals 0.625 ea Helix \\
\hline
\end{tabular}


Table 2. Geometry of Test Gear Sets

\begin{tabular}{|c|c|c|c|c|c|}
\hline & & & & tact $R$ & tios \\
\hline Configuration & Tooth Form & Type & Profile & Face & Total \\
\hline $\begin{array}{l}\text { 1. Conventional Spur } \\
\text { Baseline }\end{array}$ & Involute & Spur & 1.43 & 0.00 & 1.43 \\
\hline 2. HCR-INV & Involute & Spur & 2.10 & 0.00 & 2.10 \\
\hline $\begin{array}{l}\text { 3. Conventional Single } \\
\text { Helical Baseline }\end{array}$ & Involute & Helical & 1.38 & 1,25 & 2.63 \\
\hline 4. Double Helical & Involute & Helical & 1.41 & 2.27 & 3.68 \\
\hline 5. Helical-INV & Involute & Helical & 1.37 & 1.76 & 3.13 \\
\hline 6. HCR Helical-INV & Involute & Helical & 2.12 & 2.25 & 4.37 \\
\hline 7. NIF Baseline & Nonlnvolute & Spur & 1.43 & 0.00 & 1.43 \\
\hline 8. NIF.HC & Nonlnvolute & Spur & 2.20 & 0.00 & 2.20 \\
\hline
\end{tabular}

high contact ratio spur gear pair and several helical gear geometries that includes a double helical gear pair. The gears were ground to an aircraft quality (AGMA class 12) with virtually straight leads (no crowning). In most of the gear pairs, both the gear and the pinion had both tip and root relief that started at the pitch and tapered fairly linearly to the tip and root, respectively (see Fig. 4). Except for the double helical pair, the sets have the same inertias and the same mounting configuration. The width of the double helical set is somewhat greater than the others due to the gap between the two helices and the bearings used to support the double helicals were different than the other sets.

Gear pairs 7 and 8 are two heavily modified sets that have the purported advantage of having a more constant radius of curvature, thus enhancing both surface durability and scoring resistance.

Tests were run at three speeds $(3000,4000$ and 5000 $\mathrm{rpm}$ ) and three torques (1361, 1816, and $2269 \mathrm{lbf}-\mathrm{in}$.). The middle load almost always had response levels in between the two extreme loads, both in the experiment and in the LDP simulation, so it is felt that just presenting the extreme loads provides a good feel for the results.

\section{Noise Results}

The Drago, et al.[12] presentation of noise results used the sum of the amplitudes of the first three gear mesh harmonics as well as sidebands about these harmonics to compute overall sound power levels in $\mathrm{dB}$. However, in reviewing the harmonic data it was observed that each harmonic was significantly affected by gear test rig dynamics, since at some speeds the mesh frequency dominated and at other speeds one of the higher harmonics dominated the sound power level. Likewise, the LDP predictions provide information on each harmonic, so it is logical that the experimental and predicted data are presented one harmonic at a time.

Therefore, Figs. 1-3 summarize the experimentally generated data base for each of the respective harmonics of mesh frequency. The ten bar charts for each test condition include sound power data from three separate test runs of the "baseline" spur gear pair (gear pair number \#1) and data for each of the other test gear pairs given in Table 2. A tremendous amount of data is presented in these three figures, however, a cursory scan of them shows several trends, some of which have been pointed out by Drago et al. [12]:

1. The statistical variation in sound powers of the three "repeat" runs of the reference gear pair is usually about $2-4 \mathrm{~dB}$.

2. At each test condition, the trends from one gear pair to the next for each harmonic are quite similar, i.e. in most cases the non-involute gears numbered 7 and 8 have the highest sound power levels, the spur gear pair \#1 is next highest, and the helical gears are consistently the quietest.

3. With the exception of gear pairs 7 and 8 , there is a definite correlation between sound power level and total contact ratio for each of the harmonics of mesh frequency.

4. In every case, gear pair 6 , the high profile/high face contact ratio helical set, has the lowest sound power level.

5. There is a strong speed effect, as indicated by the relative amplitudes of the harmonics at each speed. For instance, the third harmonic has the highest levels at $3000 \mathrm{rpm}$, the second harmonic is highest at $4000 \mathrm{mpm}$ and the fundamental harmonic is highest at $5000 \mathrm{rpm}$. Although not shown, a three-dimensional "waterfall" plot verified that these "high" levels at harmonics are indeed influenced by system resonances. It is interesting to note that the first harmonic amplitudes shifted by as much as $25 \mathrm{~dB}$ as speed was changed. These wide shifts in measured sound power amplitudes are due to the dynamics of some part of the shafting/housing system that are certainly important in ascertaining the noise radiation. These dynamics are not being evaluated in this paper, but by considering one operating condition at a time when comparing the performance of the gear sets, these dynamic effects are essentially "normalized" out.

\section{Load Distribution Program Modeling of Profile Modifications}

The Load Distribution Program uses a simplex type algorithm [13] to compute the load distribution along the lines of contact of spur and helical gears. The prediction of transmission error of the gear set is a byproduct of the load distribution computation. Also computed in the program are root stresses [14], time varying bending moments, and bearing forces. The deflections accounted for in the computation include tooth bending and shear using a Rayleigh Ritz procecture[15,16], Hertzian deflection, tooth base rotation and base translation [17], shaft deflections, and bearing and housing deflections. Intentional deviations from perfect teeth, including profile and lead modifications are accounted for, as are misalignment errors and tooth manufacturing errors that include. pressure angle errors, spacing errors, and lead errors. Errors and modifications may be entered as combinations of straight lines, parabolas, and/or circular forms or may be entered from digitized profile and/or lead checks. Multi-variable analysis is possible [18] so that 


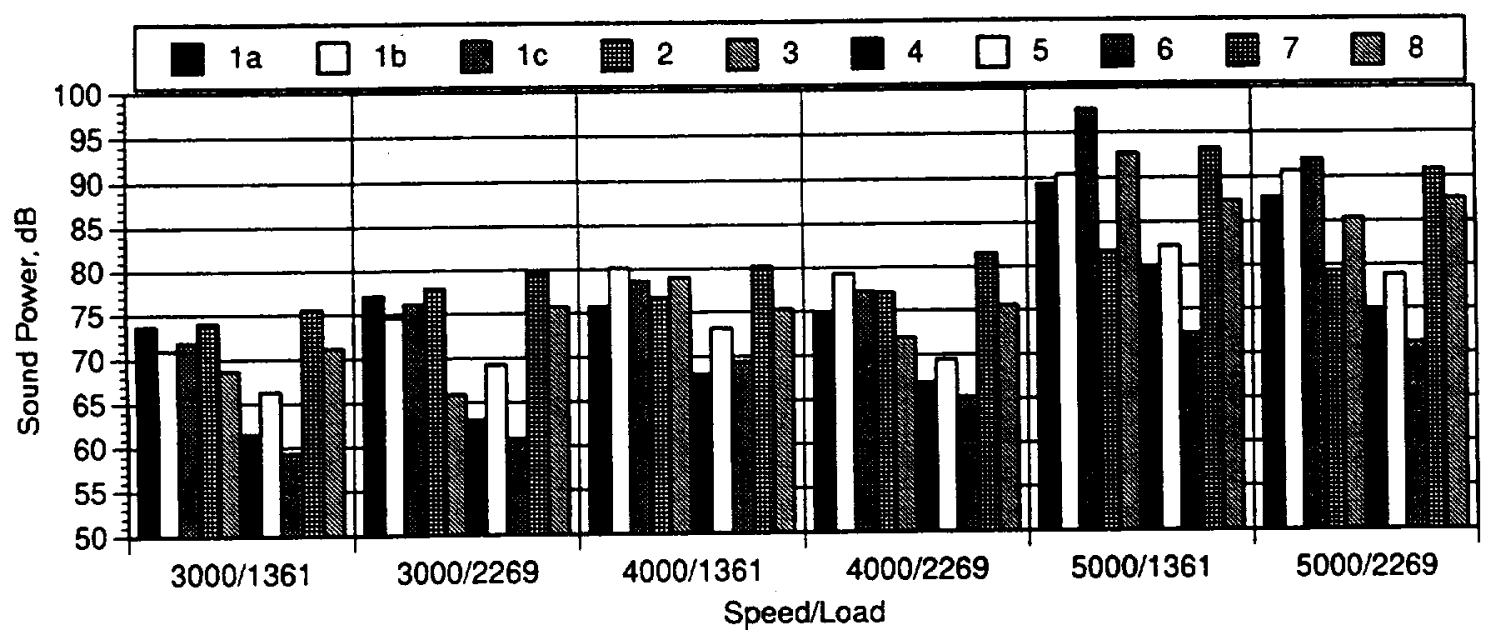

Fig. 1. Summary of the Sound Power at Mesh Frequency (Including Two Adjacent Sideband Pairs) for Each of the Test Gear Pairs

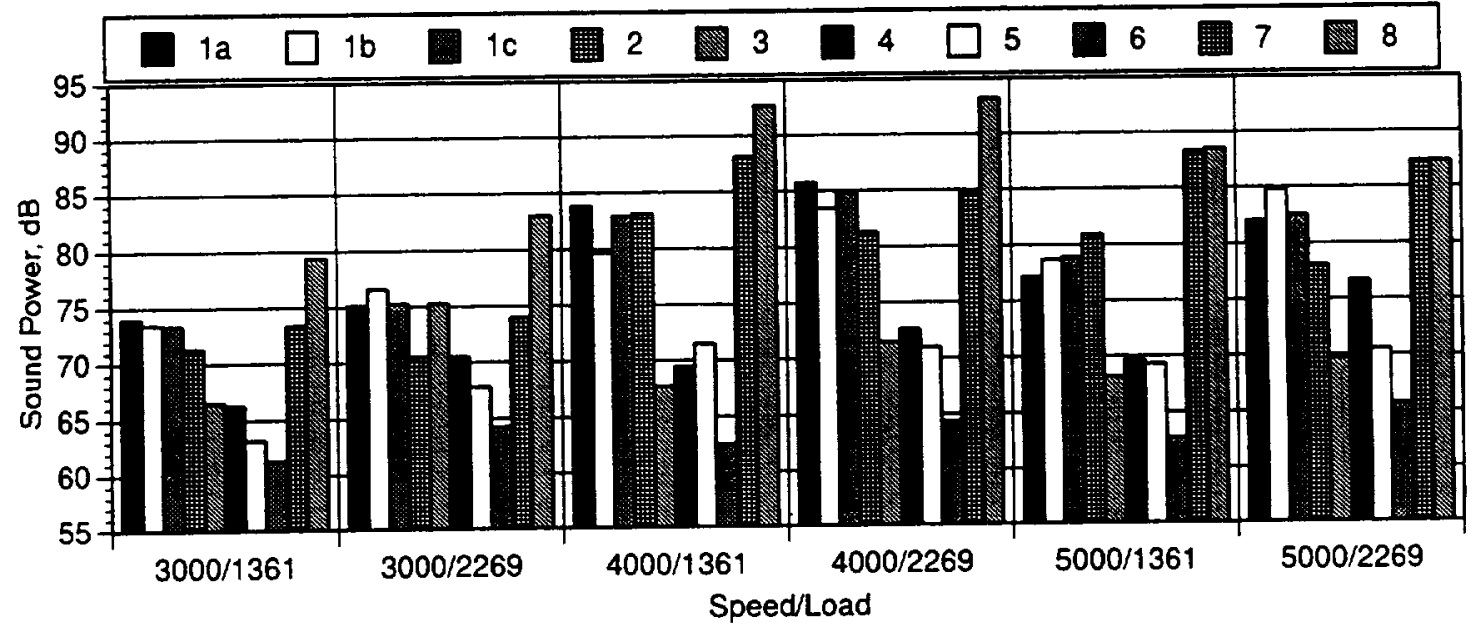

Fig. 2. Summary of the Sound Power at Twice Mesh Frequency (Including Two Adjacent Sideband Pairs) for Each of the Test Gear Pairs

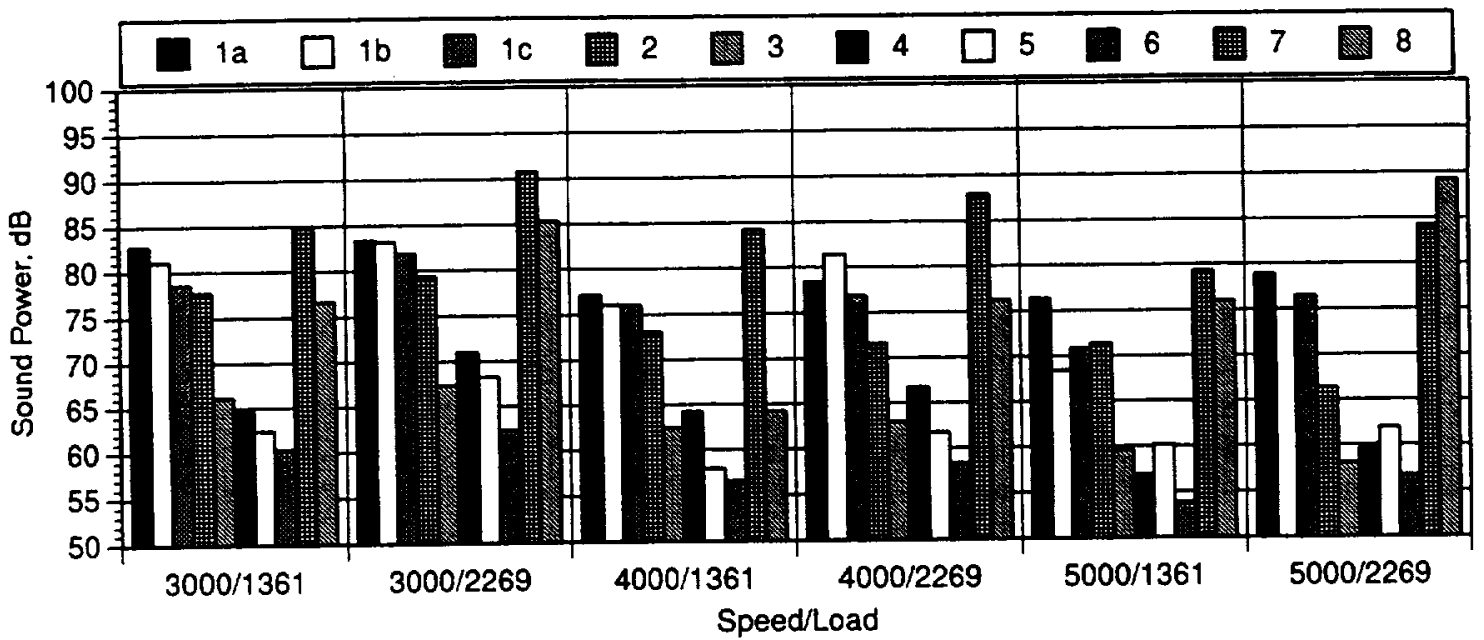

Fig. 3. Summary of the Sound Power at Three Times Mesh Frequency (Including Two Adjacent Sideband Pairs) for Each of the Test Gear Pairs 
- manufacturing sensitivities are easily studied. Several of these features will be shown in the analysis of the test gears.

It has long been understood that profile modifications, especially for spur gears, provide certain advantages in designing quiet gears $[1,19,20]$ It has been shown that conventional tip and/or root relief give a minimum noise at only one operating load $[7,20,21]$. Fig. 4 shows the profile modifications for the baseline spur gear and pinion, respectively (gear pair 1). These charts are fairly typical of those of gear pairs 1-6, with the amplitudes and shapes changing a small amount for each gear pair. Although LDP accepts the digitized input of profile charts, it was found that each of the inspection charts could be emulated in LDP with combinations of straight lines and parabolas. Using these approximations also allows for some eyeball averaging of the individual profile charts.
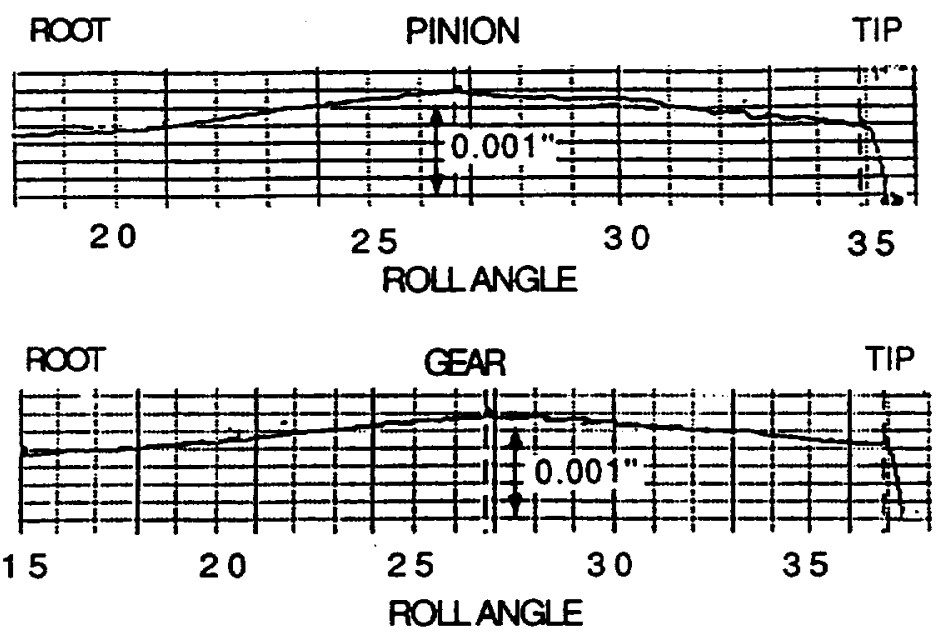

Fig. 4. Measured Profiles of the Baseline Spur Gear Pair

Fig. 5 shows the profiles created in LDP to simulate the profile charts of Fig. 4.. The last curve in Fig. 5 provides the sum of the modifications of the pinion and gear when added at their corresponding roll angles for each contact position. This last figure is the "effective" tooth pair modification.

As an example of the LDP analysis, both the baseline spur gear pair and the high contact ratio spur gear pair (Pair \#2) will be used to show typical LDP results. 1. Fig. 6 shows a "poor person's" load contour map for the 11 contact positions of the baseline spur gear set (gear pair \#1). In this Figure, load intensity is normalized such that the higher loads have higher numbers so that a "zero" indicates no contact and a nine is a the highest load intensity. Here, contact extends across the entire profile (no zeros) and tapers towards zero at the tips, indicating that the modification was selected quite well The predicted transmission enror trace over one mesh cycle and the amplitudes of the first three mesh frequency harmonics are presented in Fig. 7.

When the amplitude of the mesh frequency harmonic of transmission error is plotted versus torque of the spur gear
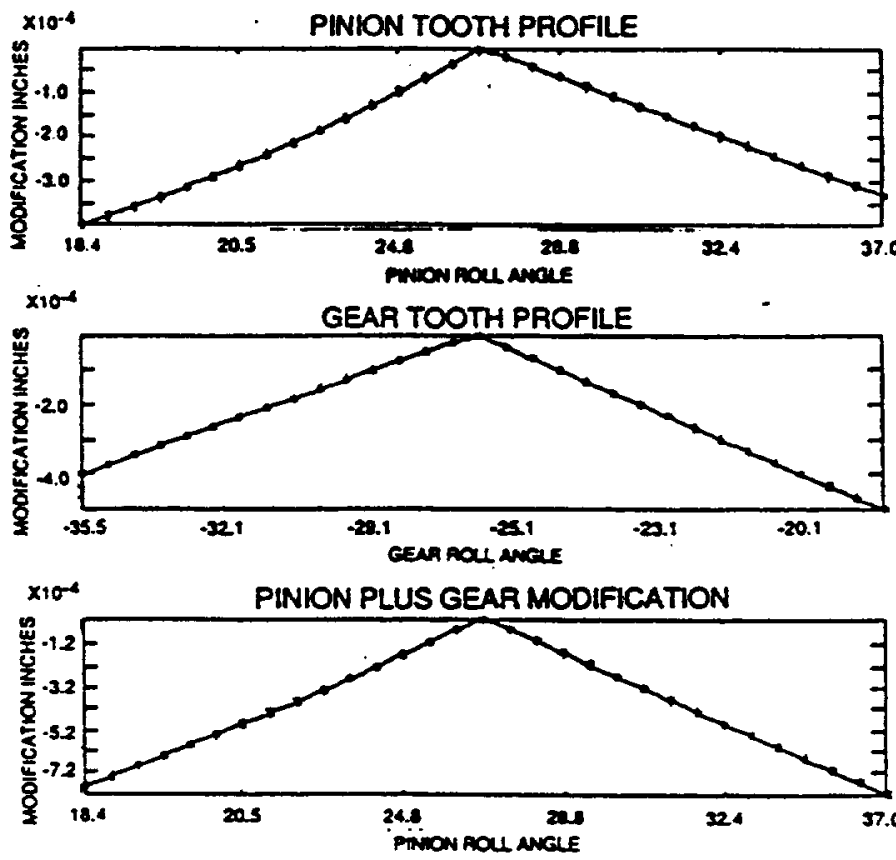

Fig. 5. Profiles used in the LDP Simulation of the Baseline Spur Gear Pair

PRESSURE SCALEO BETWEEN O AND 9

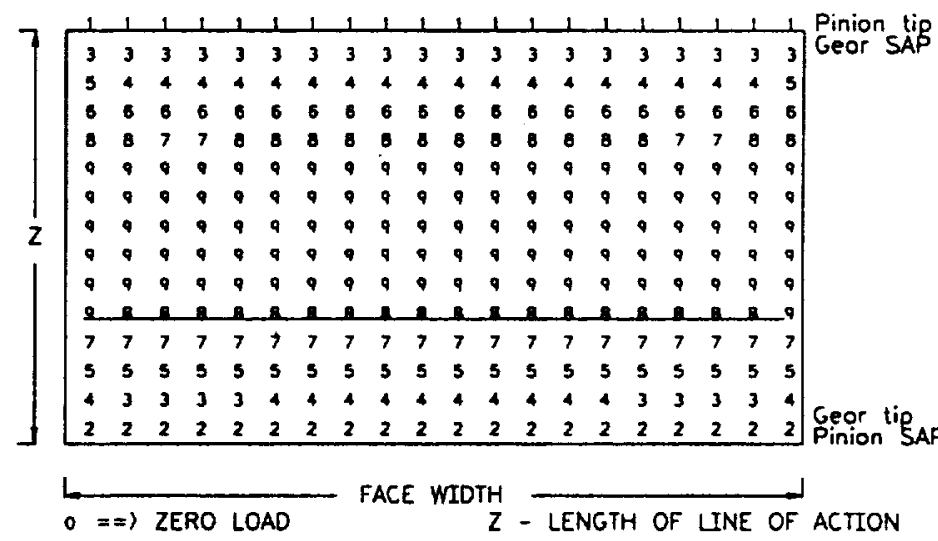

Fig. 6 Predicted Load Intensity Distribution for the Baseline Spur Gear Pair Operating at 2269 lbf-in.

pair, one sees in Fig. 8 that the minimum transmission error occurs at a much higher torque than the applied torques of 1361 and $2269 \mathrm{lbf}$-in., respectively. One of the actual profiles was digitized for this gear and it was found to give only a slightly different transmission error trace from that shown in Fig. 7. The differences between the digitized and the approximate profiles were always found to be less than the geometry variations that are encountered going from one tooth to the next.

Fig. 9 shows a load contour plot for the high contact ratio pair operating at $2269 \mathrm{lbf}$-in. In this case, one sees that the modification is such that contact does not reach the tip of either the pinion or the gear. The traditional interpretation 


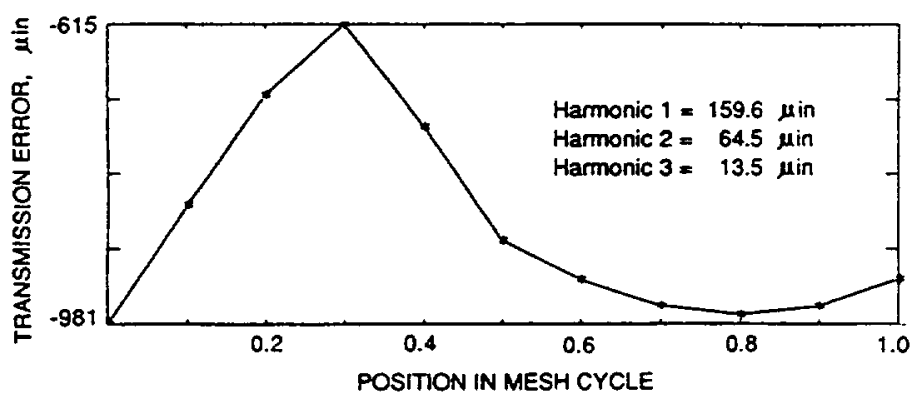

Fig. 7 Predicted Transmission Error of the Baseline Spur Gear Pair Operating at $2269 \mathrm{lbf}$-in.

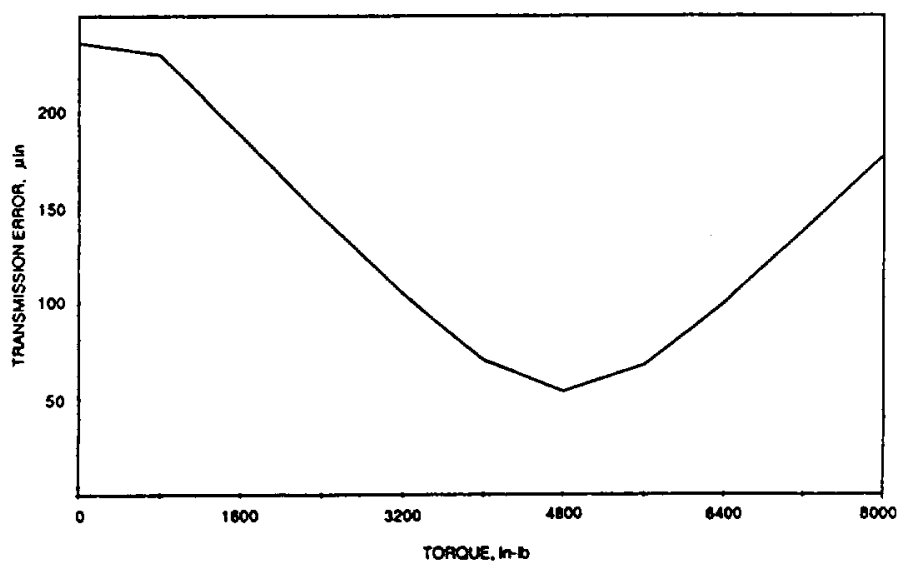

Fig. 8. Effect of Torque on Mesh Frequency Harmonic of the Predicted Transmission Error of the Baseline Spur Gear Pair

would be that the modification is slightly high for the gear set when operating at this load. In most of the other gear sets, the predicted contact patterns are close to those of Fig. 9. Similar contact patterns were observed in the actual testing.

Fig. 10 shows a different means of interpreting the load sharing between the high contact ratio spur gears. Here, the predicted force carried by three consecutive pairs of teeth through one mesh cycle are plotted. If one places end to end the traces of tooth pairs 3,2 , and 1 , respectively, the tooth force trace for a single tooth would be created. The interpretation of this figure is that the modification is functioning very well - there are no discontinuities in the tooth forces and there are literally two pairs of teeth in contact throughout the mesh cycle giving an effective contact ratio of just under 2.0. Since a goal of high contact ratio teeth is to have a contact ratio of 2.0 or greater, this modification seems to work well. The fact that the contact of Fig. 9 does not reach the tooth tips is verified here, since the operating contact ratio is somewhat less than the theoretical contact ratio of 2.10 .

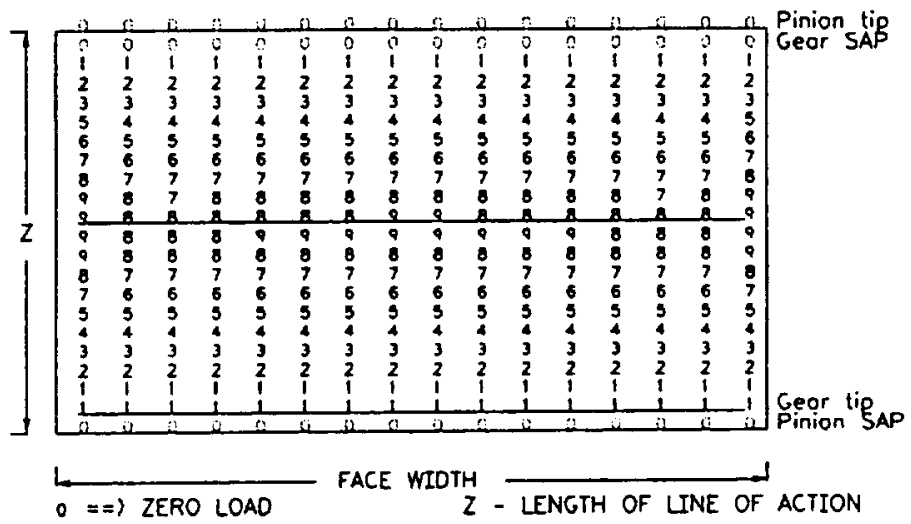

Fig. 9. Predicted Load Intensity Distribution for the High Contact Ratio Spur Gear Pair Operating at 2269 lbfin.

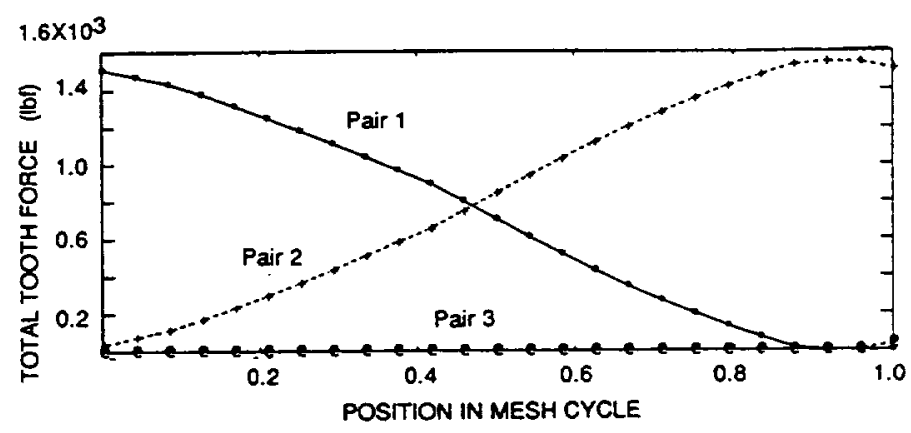

Fig. 10. Predicted Mesh Cycle Forces Carried by High Contact Ratio Tooth Pairs Operating at 2269 lbf-in.

\section{Transmission Error Prediction/Measurement}

Similar procedures were followed in modeling all 8 gear sets. The tricky exception is the double helical gear, since the standard LDP program does not have the capability of modeling this type of gear. However, in a previous study using a modification of LDP for double helical gears it was found that as long as each helix has the same profile and lead modifications, it is possible to model just half the mesh using one-half of the total load and the same results will be obtained [22].

Fig. 11 presents a bar chart of the predicted amplitudes of the mesh frequency transmission error at each harmonic for each of the test gear pairs. The decibel values are referenced to 0.1 micro-inch so that the predicted transmission errors at each harmonic range from close to 0.1 microinch for the third harmonic of gear pair 5 to over 300 micro-inches for the first harmonic of gear pair 7. In general, one sees that for each gear set, as the harmonic number increases, the amplitude of transmission error decreases. It was also found in the modeling process that the predictions of the higher harmonic amplitudes were much more sensitive to slight changes in the profile modifications than was the mesh frequency harmonic. 
When comparing individual gear sets, it is observed that in most instances, there is a good qualitative conclusion that as contact ratio increases, transmission error decreases. This is the same conclusion reached by other investigators $[1,5]$ and also is similar to the noise measurement conclusion of Drago et al.[12]. In fact, if the gears are ranked in order of quietness for each harmonic, one finds that in most instances the rankings for transmission error of Fig. 11 are the same as the rankings for noise for Figs. 1-3.

One notable exception is the double helical gear pair (pair \#4) which has a higher contact ratio than gear pair \#5, the conventional helical gear set. Here, the predicted transmission errors are always slightly greater for the double helicals than for the regular helicals. Reasons for this discrepancy could be due to the reduction in the thrust load for the double helicals or due to the increased inertia of the double helicals due to the added material in the gap between the individual helices.

In almost every case, the transmission error predictions of the mesh frequency harmonic decrease when increasing the load from $1361 \mathrm{lbf}$-in to $2269 \mathrm{lbf}$-in. This is because each of the gear pairs has an "optimum" load curve similar to Fig. 8. and most of the gear pairs are operating to the left side of the curve. A major difference that was observed in these curves as contact ratio was increased is that the slopes on either side of the "optimum" are much less, indicating a lower load sensitivity as contact ratio increases. This reduced load sensitivity is one of the major advantages of increasing the contact ratio of gears. This load sensitivity trend is not as apparent for the higher harmonics of mesh frequency.

In order to be able to condense the comparis ons of the experiment and the predictions, we will use the scheme used by Drago, et al.[12], where they compared the noise of each of the gear pairs with the base-line spur gear pair (pair 1). This method of comparison should also normalize out any dynamic effects since the dynamics should be the same for each set of gears (the exception might be the double helical gears whose inertias are greater than the other gears. In this case, the first of the experimentally measured sound power levels of the base-line spur pair (pair \#1a) of Figs. 1-3 was used for each harmonic's reference value.

Fig. 12 shows the comparison of the LDP predictions with the measured sound reductions of the first harmonic (mesh frequency) at $3000 \mathrm{rpm}$. For this condition, as with the subsequent conditions, data is always presented as a reduction in either transmission error or sound power with respect to the baseline spur gear set. This presentation method, which is logarithmic on each axis, essentially normalizes the results so that comparisons can be made without knowing the transmission error to noise coupling efficiency. Individual gear pairs are labeled on the plot, with the letter $\mathrm{A}$ indicating the lower torque and the letter $\mathrm{C}$ indicating the higher torque. It is felt that the $3000 \mathrm{rpm}$ results should correlate best with the static predictions of LDP since the lowest speed should have the lowest amount of dynamics.
The correlation in Fig. 12 is roughly linear and the major deviations from the straight line correlation are the high contact ratio spur gear pair (pair \#2) and the double helical pair (pair \#4). The trends are similar but with more scatter for the comparisons at $4000 \mathrm{rm}$ and $5000 \mathrm{rpm}$ that are respectively presented in Figs. 13 and 14. Second harmonic comparisons for all speeds are presented in Fig. 15 and third harmonic data are presented in Fig. 16. It appears that as the harmonic number goes up, there is more scatter in the comparison. This might be expected, since higher harmonics are affected more by minute changes that could be encountered in modeling the profiles or in changes in the test setup.

Even though transmission error is purported to be closely allied with noise level, the data does not seem to show a universal constant that correlates the two values. This constant, which is obtained from the slope of the best straight line fit of the sound power vs transmission error curve, is 0.56 for $3000 \mathrm{mpm}, 0.37$ for $4000 \mathrm{rpm}$ and 0.55 for the 5000 rpm data. Because of system sensitivities such as system dynamics, force transmission paths and housing characteristics one would expect this constant to change from one system to the next and from one frequency to the next. Also, the effect of helix angle on the force coupling between the shaft and the housing might have a significant effect on this constant.

In Figs. 12-16, each data point is affected by many factors which could cause the point to have a different location on the plot. These factors include measurement variation and measurement error on the vertical axis and modeling variability on the horizontal axis. A simple analysis of measurement variability can be made from Figs. 1-3 which show a 2-4 dB sound power variation due to simply remounting the same set of spur gears. Since this gear set is used as the reference for the plots, any errors in measurement or modeling will affect the "zero" position of Figs 12-16. However, this change would not significantly affect the slope constants mentioned in the previous paragraph. There are also issues of accuracy of the error charts that were used in LDP, mounting misalignment, errors in modeling of tooth compliance, etc., that should provide horizontal spread in each data point. These issues could be studied with the model in order to determine each gear pair's sensitivity to these factors.

\section{$\underline{\text { Summary }}$}

This paper has shown that at any one operating condition and measurement frequency there is a reasonable correlation between predicted transmission error and measured sound power levels. This correlation is better for the mesh frequency harmonic and decreases as the harmonic number is increased. Many of the variations are well within what are projected to be variations of profiles from tooth to tooth, modeling errors, tooth measurement errors and testing variations. These issues will be addressed in future studies of these data. Also, the seemingly high prediction of noise 


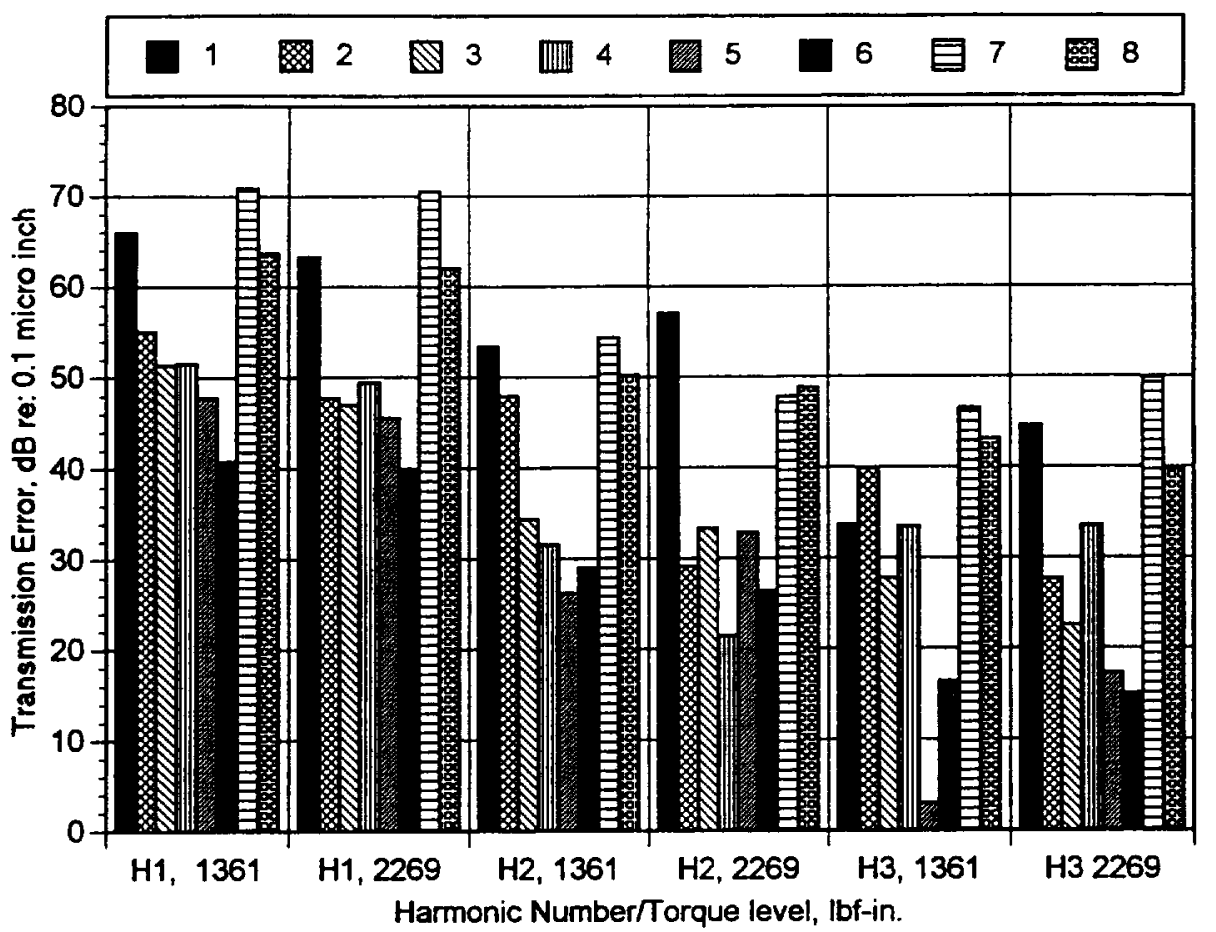

Fig. 11. Summary Chart of Predicted Transmission Errors for Each of the First Three Mesh Harmonics at both 1361 and 2269 lbf-in.

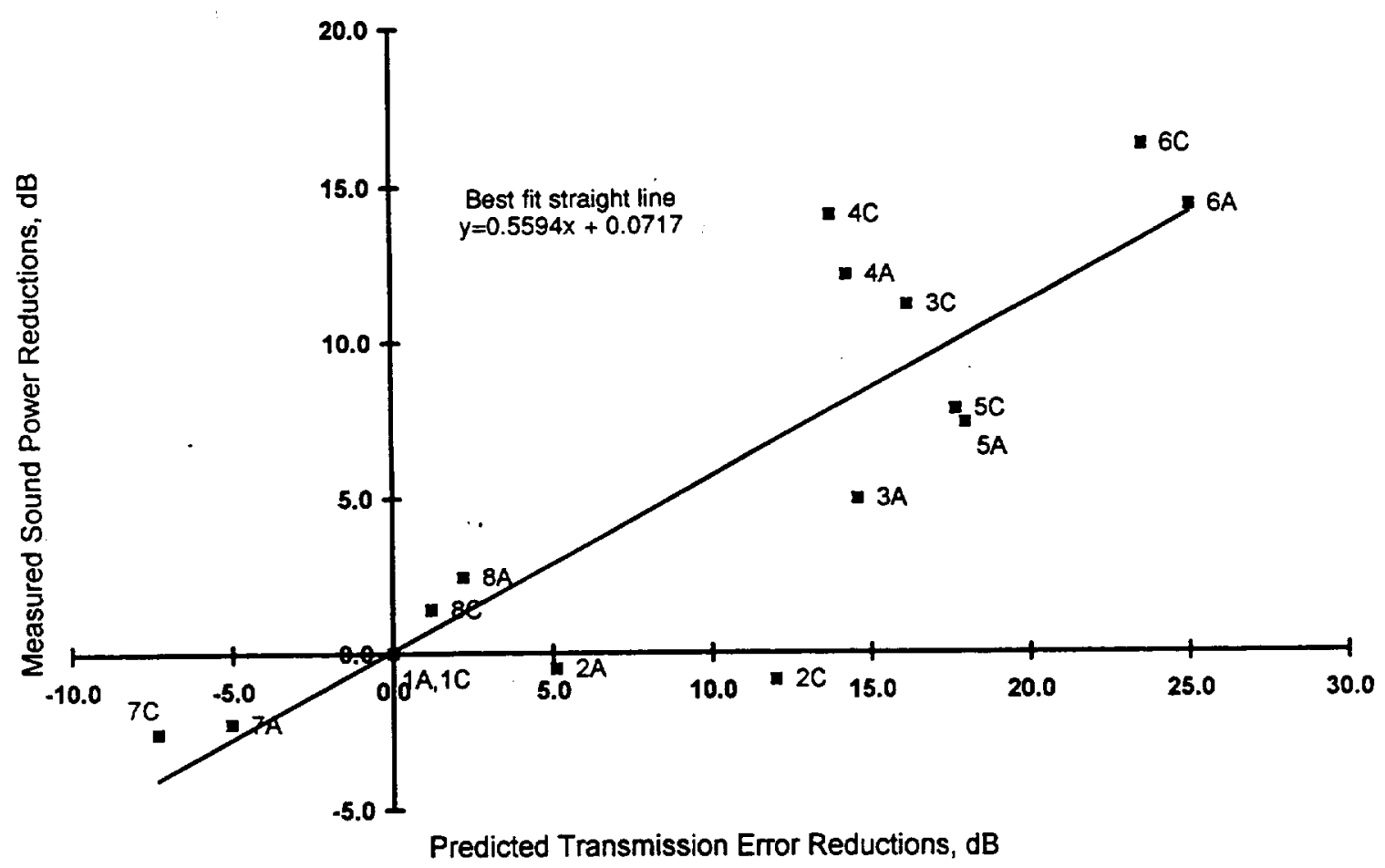

Fig. 12. Comparison of Predicted Transmission Error with Measured Sound Power Levels for the Mesh Frequency Harmonic at 3000 rpm (Data Reported as Reductions from Baseline Spur Gear set). 


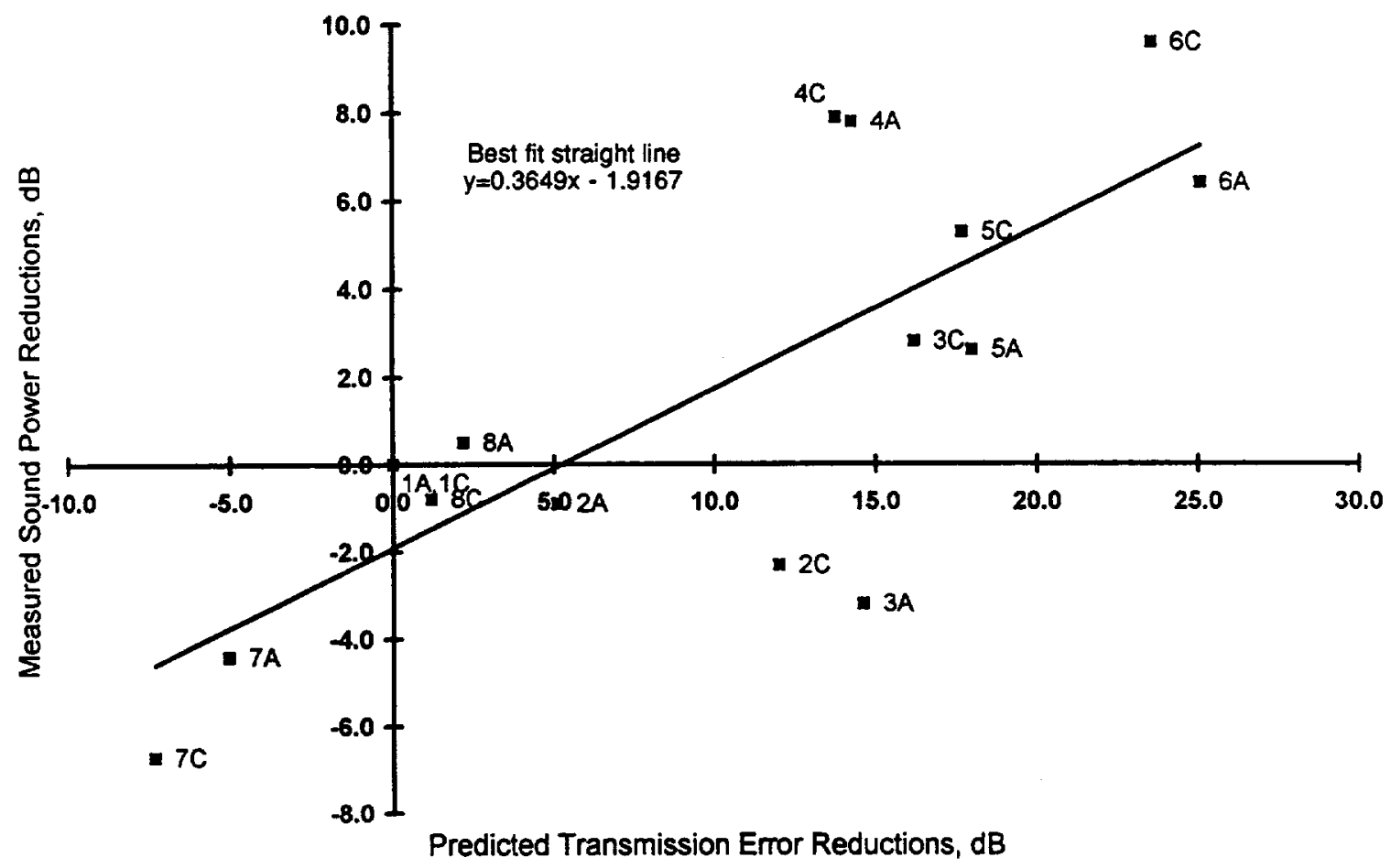

Fig. 13. Comparison of Predicted Transmission Error with Measured Sound Power Levels for the Mesh Frequency Harmonic at $4000 \mathrm{~mm}$ (Data Reported as Reductions from Baseline Spur Gear set).

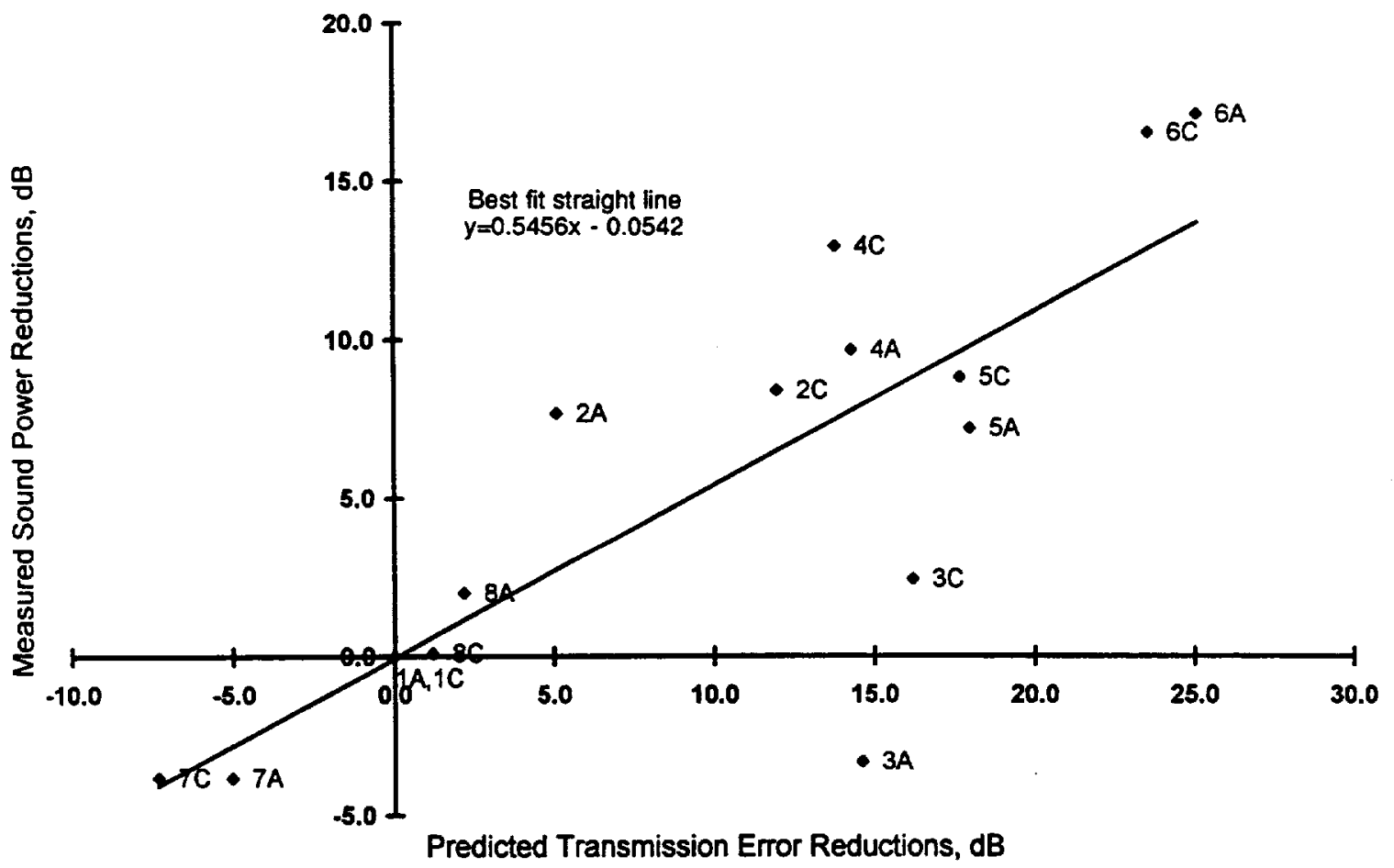

Fig. 14. Comparison of Predicted Transmission Error with Measured Sound Power Levels for the Mesh Frequency Harmonic at 5000 rpm (Data Reported as Recuctions from Baseline Spur Gear set). 


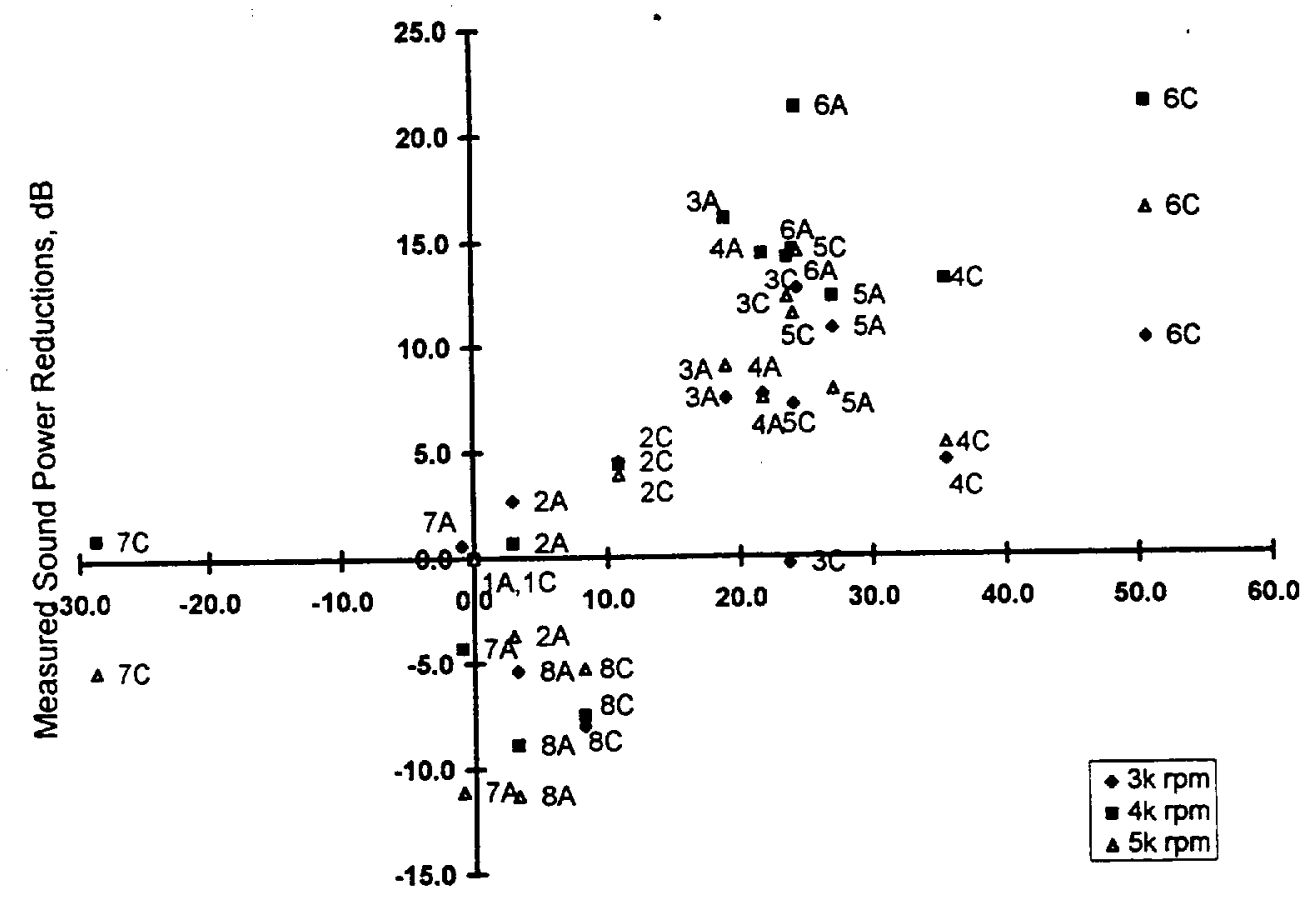

Predicted Transmission Error Reductions, dB

Fig. 15. Comparison of Predicted Transmission Error with Measured Sound Power Levels for the Second Harmonic of Mesh Frequency (Data Reported as Rectuctions from Baseline Spur Gear set).

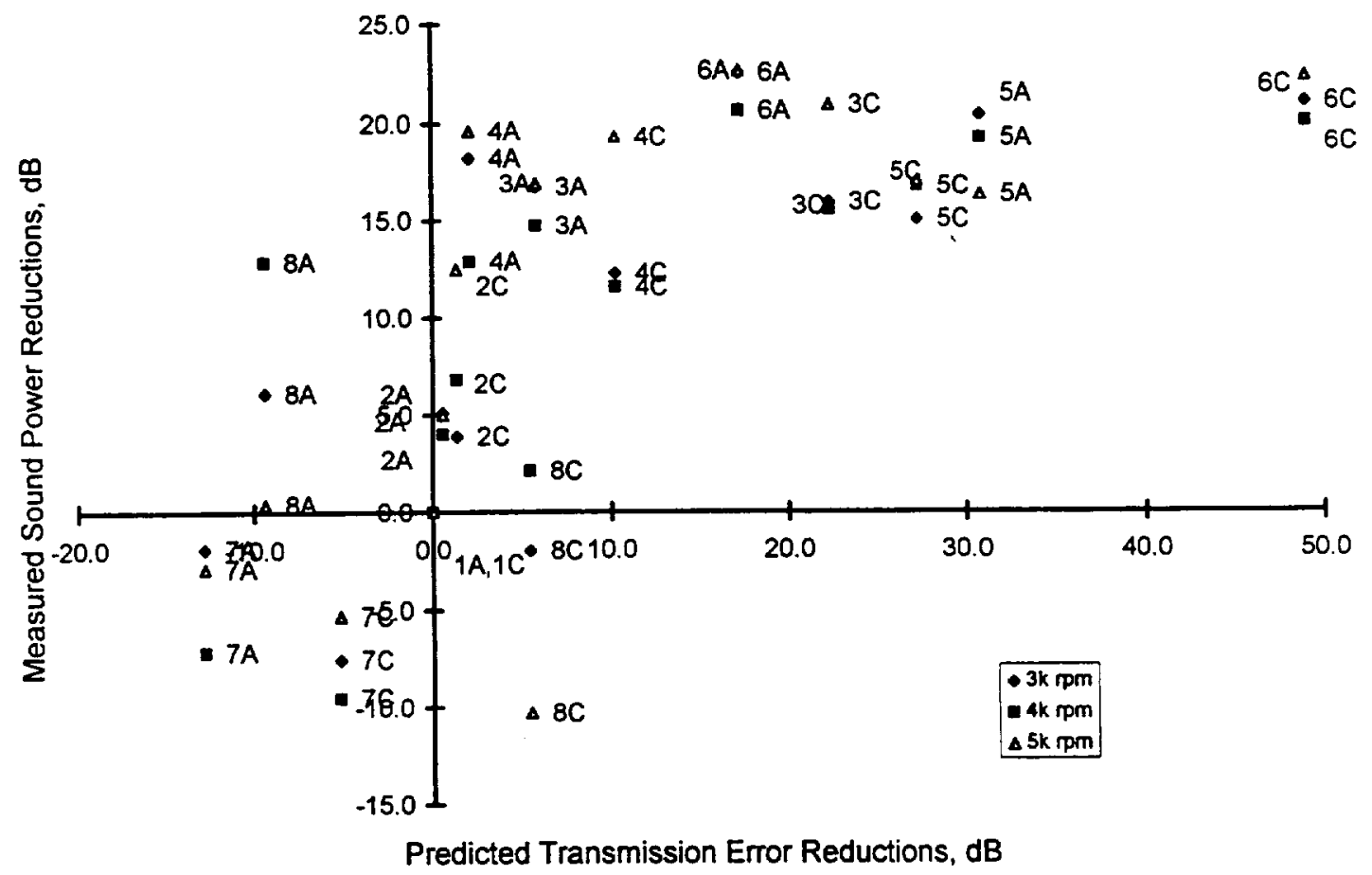

Fig. 16. Comparison of Predicted Transmission Error with Measured Sound Power Levels for the Third Harmonic of Mesh Frequency (Data Reported as Reductions from Baseline Spur Gear set). 
reduction for the high contact ratio spur gear pair needs to be studied in more detail. Perhaps other noise generation sources in the high contact ratio spur gears cancel out the transmission error gains. Finally, additional gears should be cut that have modifications that are optimized for the test load. In some of the simulations that were run, further noise reductions of as high as $20 \mathrm{~dB}$ below the "best" reductions of gear pair 6 were predicted using LDP. Since other excitation sources [1] are likely to start dominating after the primary excitation is nearly eliminated, it is not expected that the measured sound power reduction will be as great as the predicted transmission error reduction for the optimally designed gears.

\section{Acknowledgments}

The authors wish to acknowledge the US Amy Research Office (Grant DAA03-92-G-0120, Dr. T.L. Doligalski technical monitor) and the US Army Research Laboratory, NASA Lewis, for their support of the research which is the basis of this paper.

\section{References}

1. Houser, D.R, "Gear Noise" Chapter 16 in Dudley's Gear Noise Handbook , D. Townsend, Editor, McGraw Hill, 1992.

2. Welboum, D. B., "Fundamental Knowledge of Gear Noise - A Survey," Proc., Noise \& Vib. of Engines and Transmissions., I. Mech. E., Cranfield, UK, July 1979, pp. 9-14.

3. Smith, J. D., Gears and Their Vibration, The Macmillan Press Ltd., New York, 1983.

4. Smith, R.E., "The Relationship of Measured Gear Noise to Measured Gear Transmission Errors," AGMA Paper 87FTM6, Cincinnati, 1987.

5. Mark, W. D., "Gear Noise Excitation," Engine Noise: Excitation, Vibration, and Radiation, New York, NY: Plenum Press, 1982.

6. Winter, H., Gerber, H., and Muller, R., "Investigations on the Excitation of Vibrations and Noise at Spur and Helical Gears," Proc., 1989 ASME Intl. Power Trans. \& Gearing Conf., Chicago, Apr. 1989, pp. 765-779.

7. Niemann, G., Baethge, J. "Drehwegfehler, Zahnfederharte und Gerausch bei Stimradem," VDI-Z, Vol. 2, No. 4, 1970. pp. 205-214 and No. 8 pp. 475-499.

8. Opitz, H., "Noise of Gears," Philos. Trans. of the Royal Society, Vol. 263, Dec. 1968, pp. 369-380.

9. Houser, D. R, "Gear Noise Sources and Their Prediction using Mathematical Models," Chapter 16 of Gear Design Manufacturing and Inspection Manual, Society of Automotive Engineers, 1990. pp 213-222.

10. II, M., "Some Problems of Gear Noise and Quality Control," Vib. and Noise in Motor Veh., I. Mech. E, 1972, pp. 82-90.

11. Kubo, A., Nonaka, T., Kato, N, Kato, S, Ohmori, T., "Representative Form Accuracy of Gear Tooth Flanks on the Prediction of Vibration and Noise of Power
Transmissions," Transactions of JSME Vol. 56, No. 532, 1990. pp. 238-243.

12. Drago, R., Lenski, J.W., Spencer, R.H., Valco, M.J., Oswald, F.B. "The Relative Noise Levels of Parallel Axis Gear Sets with Various Contact Ratios \& Gear Tooth Forms," AGMA Paper , Proc., Fall Technical Meeting, October, 1993.

13. Conry, T.F. and Seireg, A., "A Mathematical Programming Technique for the Evaluation of Load Distribution and Optimal Modifications for Gear Systems," J. Eng. Ind., Trans. ASME, Vol. 95, 11151122.

14. Clapper, M.L., Houser, D.R, "Prediction of Fully Reversed Stresses at the Base of the Root in Spur and Double Helical Gears in a Split Torque Helicopter Transmission," Proc. American Helicopter Society Rotary Wing Specialists Meeting, Williamsburg, VA October, 1993.

15. Yakubek, D., Busby, H.R, and Houser, D.R., "ThreeDimensional Deflection Analysis of Gear Teeth using both Finite Element Analysis and a Tapered Plate Approximation," AGMA Paper 85FTM4, October, 1985.

16. Yau, E., Busby, H., Houser, D.R., "A Rayleigh-Ritz Approach for Modeling the Bending Deflections of Gear Teeth," Proc., MPT 91, International Conference on Motion and Power Transmission, Hiroshima, Nov. 1991. pp. 572-577.

17. Stegemiller, M., Houser, D.R., "A Three Dimensional Analysis of the Base Flexibility of Gear Teeth," Proceedings, ASME Power Transmission and Gearing Conference, Chicago, pp. 189-196, 1989. Also J. Mechanical Design, Transactions, ASME, March, 1993.

18. Sundaresan, S., Ishii, K., and Houser, D.R. "A Procedure that Accounts for Manufacturing Errors in the Design Minimization of Transmission Error in Helical Gears," American Gear Manufacturers Association(AGMA) Fall Technical Meeting, Toronto, Canada. September, 1990.

19. Munro, RG., Yildrim, N., Hall, D.M., "Optimum Profile Relief and Transmission Error in Spur Gears," Proc. IMechE Gear Noise and Vibration, Apr. 1990, Cambridge, pp. 35-42.

20. Drago, R. J., "How to Design Quiet Transmissions," Mach. Des., Dec. 11,1980, pp. 175-181.

21. Tavakoli, M.S., and Houser, D.R., "Optimum Profile Modifications for the Minimization of Static Transmission Errors of Spur Gears," J. Mech., Trans., Aut. in Design., Trans. ASME, Vol. 108, Mar. 1986, pp. 86-95.

22. Thomas, J., Houser, D.R, "A Procedure for Predicting the Load Distribution and Transmission Error Characteristics of Double Helical Gears," Proc. 2nd International Conference on Gearing, Paris, Feb. 1992. 
Public reporting burden for this collection of intormation is estimated to average 1 hour per response, including the time for reviewing instructions, searching existing data sources, gathering and maintaining the data needed. and completing and reviewing the collection of information. Send comments regarding this burden estimate or any other aspect of this collection of information, including suggestions for reducing this burden, to Washington Headquarters Services. Diractorate for Information Operations and Reports, 1215 Jefferson Davis Highway, Suite 1204, Arlington, VA 22202-4302, and to the Office of Management and Budget, Papenwork Reduction Project (0704-0188), Washington, DC 20503.

\begin{tabular}{|l|l|l|}
\hline 1. AGENCY USE ONLY (Leave blank) & $\begin{array}{c}\text { 2. REPORT DATE } \\
\text { June } 1994\end{array}$ & $\begin{array}{c}\text { 3. REPORT TYPE AND DATES COVERED } \\
\text { Technical Memorandum }\end{array}$ \\
\hline
\end{tabular}

\section{TITLE AND SUBTITLE}

Comparison of Transmission Error Predictions With Noise Measurements for Several Spur and Helical Gears

5. FUNDING NUMBERS

$$
\text { WU-505-62-36 }
$$

6. AUTHOR(S)

Donald R. Houser, Fred B. Oswald, Mark J. Valco, Raymond J. Drago, and Joseph W. Lenski, Jr.

7. PERforming oRganization NAME(S) AND ADDRESS(ES) NASA Lewis Research Center Cleveland, Ohio 44135-3191 and Vehicle Propulsion Directorate U.S. Army Research Laboratory Cleveland, Ohio 44135-3191

9. SPONSORINGMONITORING AGENCY NAME(S) AND ADDRESS(ES)

National Aeronautics and Space Administration

Washington, D.C. $20546-0001$

and

U.S. Army Research Laboratory

Adelphi, Maryland 20783-1145
8. PERFORMING ORGANIZATION REPORT NUMBER

E-8954

10. SPONSORINGMONITORING AGENCY REPORT NUMEER

NASA TM-106647

ARL-TR-493

AIAA-94-3366

11. SUPPLEMENTARY NOTES

Prepared for the 30th Joint Propulsion Conference cosponsored by the AIAA, ASME, SAE, and ASEE, Indianapolis, Indiana, June 27-29, 1994. Donald R. Houser, The Ohio State University, Columbus, Ohio 43210; Fred B. Oswald, NASA Lewis Research Center; Mark J. Valco, U.S. Army Research Laboratory, Lewis Research Center, Cleveland, Ohio 44135; Raymond J. Drago and Joseph W. Lenski, Jr., Boeing Helicopters, Philadelphia, Pennsylvania 19142. Responsible person, Fred B. Oswald, organization code 2730, (216) 433-3957.

12a. DISTRIBUTIONAVAILABILITY STATEMENT

12b. DISTRIBUTION CODE

Unclassified - Unlimited

Subject Category 37

\section{ABSTRACT (Maximum 200 mords)}

Measured sound power data from eight different spur, single and double helical gear designs are compared with predictions of transmission error by the Load Distribution Program. The sound power data was taken from the recent Army-funded Advanced Rotorcraft Transmission project. Tests were conducted in the NASA gear noise rig. Results of both test data and transmission error predictions are made for each harmonic of mesh frequency at several operating conditions. In general, the transmission error predictions compare favorably with the measured noise levels.

\begin{tabular}{|c|c|c|c|}
\hline \multicolumn{2}{|l|}{ 14. SUBJECT TERMS } & & 15. NUMBER OF PAGES \\
\hline \multirow{2}{*}{\multicolumn{3}{|c|}{$\begin{array}{l}\text { Transmission error; Gear noise; Sound power; Acoustic intensity; } \\
\text { Helical gears; Spur gears }\end{array}$}} & 12 \\
\hline & & & $\begin{array}{r}\text { 16. PRICE CODE } \\
\text { A03 }\end{array}$ \\
\hline $\begin{array}{l}\text { 17. SECURITY CLASSIFICATION } \\
\text { OF REPORT }\end{array}$ & $\begin{array}{l}\text { 18. SECURITY CLASSIFICATION } \\
\text { OF THIS PAGE }\end{array}$ & $\begin{array}{l}\text { 19. SECURITY CLASSIFCATION } \\
\text { OF ABSTRACT }\end{array}$ & 20. LIMITATION OF ABSTRACT \\
\hline Unclassified & Unclassified & Unclassified & \\
\hline
\end{tabular}

